\title{
X-RAY PULSAR IN THE CRAB NEBULA
}

R. NOVICK

Columbia University, New York, N.Y.

No text nor Summary was communicated by the Author. 